\title{
Systems of Technological Innovation
}

\author{
Tugrul U. Daim
}

Received: 22 October 2012 / Accepted: 6 November 2012 /

Published online: 18 November 2012

(C) Springer Science+Business Media New York 2012

Comprehending and defining systems for technological innovation enable us to manage technology more effectively. This issue presents five papers aiming to contribute to our understanding of such systems.

This issue is compiled with papers selected from Portland International Conference on Management of Engineering and Technology which was held in Portland, Oregon, USA in August of 2011.

Bers et al. introduce a system integrating accelerated radical innovation concept with the extended stage gate model, thus providing a system for managing radical innovations. Huang et al. on the other hand explore the evolution of an industrial network in the flat panel display industry. Sick et al. use scenarios to explore how technology development can be impacted by raw material prices.

Kwakkel and Yucel explore the Dutch electricity system using various data-mining and data visualization techniques. Their results indicate that most transition trajectories point towards a future energy supply system that is reliant on clean coal and gas. Finally, Oruc and Cunningham study the electric power industry and discuss strategic technology management issues.

The tools and methods used to explore the systems of technological innovation in the papers presented in this issue are general enough to apply to many other sectors. Each paper demonstrates how complex systems can be studied easily by using different approaches and raises further questions on the applicability. It is expected that these papers motivate further research in this direction.

T. U. Daim $(\bowtie)$

Department of Engineering and Technology Management, Portland State University, PO Box 751,

Portland, OR 97207, USA

e-mail: tugrul@etm.pdx.edu 